\title{
A Dinâmica Metodológica do Design Contemporâneo em Contextos Territoriais
}

The Methodological Dynamics of Contemporary Design in Territorial Contexts

\author{
CARVALHO, Victor Jorge de Design de Produto; Universidade do Estado de Minas Gerais/Brasil \\ victorcarvalho.dg@gmail.com \\ MACIEL, Rosilene Conceição; Mestra em Gestão Integrada do Território; Universidade do Estado \\ de Minas Gerais/Brasil \\ rmaciela@gmail.com \\ MOURÃO, Nadja Maria; Mestra em Design; Universidade do Estado de Minas Gerais/Brasil \\ nadjamourao@gmail.com
}

\section{Resumo}

Este artigo tem como objetivo apresentar e descrever métodos aplicados em diferentes projetos de design de produtos e serviços com foco no território. Identifica etapas de cada método no contexto projetual e a participação efetiva do design, apontando novas perspectivas e caminhos metodológicos. Serão apresentados três projetos realizados com base nos conceitos territoriais como estratégia de criação e posicionamento de produtos, valorizando os referenciais de origem. Estes projetos são estudos de casos que ressaltam a questão da metodologia do design e as relações construídas com o território no contexto contemporâneo. A escolha dos projetos foi feita levando em consideração a diversidade de objetivos e contextos, sendo um projeto industrial, um acadêmico e um comercial.

Palavras Chave: Design; método; metodologia; território.

\begin{abstract}
This article aims to present and describe methods applied in different design projects of goods and services with a focus on the territory. It identifies steps of each method in the design context and analyzes the effective participation of the design, pointing out new perspectives and methodological paths. Three projects will be presented and discussed that were carried out under territorial basis as a strategy of creation and positioning of products valuing the referential of origin. These are case studies that highlight the question of the design methodology and the territory in the contemporary context. The choice of projects was made taking into account the diversity of objectives and contexts, presented an industrial, academic and commercial project.
\end{abstract}

Keywords: Design; method; methodology; territory. 


\section{Introdução}

A sociedade está passando por processos de conscientização e grandes mudanças no modo de viver, e principalmente, no modo de consumir. O interesse por produtos e serviços está muito além de sua qualidade. Moraes (2009) considera que os aspectos emocionais e simbólicos dos produtos atingiram importância primária, tornando essencial, por parte dos designers, o diálogo e a tradução desses valores construídos ou consolidados ao longo de toda cadeia produtiva, de modo que contribua para garantir a integração dos atores envolvidos no processo e a transmissão desses valores aos consumidores em nível global. Ganem (2016) ressalta que no mundo contemporâneo os avanços tecnológicos e as dinâmicas de consumo permitem às pessoas acesso a produtos oriundos de pequenas regiões ou comunidades. Esta tem sido uma demanda crescente do consumidor que busca conhecer a origem e todo o processo que envolve a produção, seja de ordem técnica, social ou cultural do produto a ser consumido.

Estes valores apresentam forte ligação com o conceito de território, que envolve todos os aspectos que cercam a produção, tais como: localização, matéria prima, pessoas envolvidas (sociedade), aspectos culturais, emocionais, simbólicos e, principalmente, identitários. O designer, como profissional capaz de trabalhar conexões entre o intangível e o tangível, exerce importante função na criação da identidade do produto, aspecto cada vez mais exigido pelo mercado que valoriza a autenticidade, a originalidade, a história e a origem do produto, tanto cultural quanto local. Moraes (2009) colabora nesta questão quando aponta que muitos atributos antes desconsiderados na prática projetual e na atividade profissional do design são hoje diferenciais competitivos elevados à condição primária. Dentre eles estão o valor de estima, fatores emotivos, emocionais, psicológicos e o conceito de terroir ${ }^{1 .}$

A atuação do designer deixa de estar atrelada apenas aos aspectos físicos, formais e funcionais do produto limitando-se à relação empresa e mercado. Os designers têm atentado às relações entre toda a cadeia produtiva e ao ciclo de vida do produto. Isso significa trabalhar desde a concepção até o modo do consumo. O processo passa a se preocupar também com a sustentabilidade de um ponto de vista econômico e também social, garantindo um olhar mais amplo e ações de caráter mais integrado no desenvolvimento de um projeto (GANEM, 2016). 0 desenvolvimento de um produto ou serviço considerando o território, visa também o desenvolvimento local, possibilidades de geração de renda e grau de competitividade do produto em função dos valores agregados.

O cenário complexo da contemporaneidade exige dos designers novas competências, além de abordagens sistêmicas e transversais. Não se trata apenas de agregar valor ao produto. Tratase de uma via de mão dupla, na qual o território agrega valor ao produto e o produto valoriza também o território de uma forma cíclica e contínua. Nesse sentido, a metodologia (e novos parâmetros metodológicos) vem como ferramenta neste contexto, contribuindo para a atuação do design, permitindo flexibilidade e inovação no processo projetual trazendo olhares mais atentos e sistêmicos.

\footnotetext{
${ }^{1}$ Conceito que "envolve recursos da biodiversidade, modos tradicionais de produção, costumes e também hábitos de consumo" (KRUCKEN, 2009, p.17).
} 
Dentro das novas formas do design atuar, destacam-se neste trabalho projetos que se reconhecem vinculados a um território. São projetos que consideram e valorizam origem identitária, aspectos geográficos, culturais e sociais, dos produtos ou serviços de acordo com Krucken (2009). Trabalham com complexidades especificas, uma vez que lidam com inovação e tradição simultaneamente, equacionando valores locais e possibilidades de alcance global em diferentes níveis de competitividade.

Este artigo tem como objetivo apresentar e descrever métodos aplicados em diferentes projetos de design de produtos e serviços com foco no território. Identifica etapas de cada método no contexto projetual e a participação efetiva do design, apontando novas perspectivas e caminhos metodológicos. São apresentados três projetos realizados sob-base territorial como estratégia de criação e posicionamento de produtos valorizando os referenciais de origem. Os estudos de casos ressaltam a questão da metodologia do design e do território no contexto contemporâneo. A escolha dos projetos foi feita levando em consideração a diversidade de objetivos e contextos, sendo um projeto industrial, um acadêmico e um comercial. Antes de apresentar os projetos, segue uma síntese dos apontamentos teóricos que fundamentam o trabalho de investigação.

\section{O Design Contemporâneo}

Segundo Krucken (2016), vivemos em um momento de transição que muitos autores intitulam como sociedade pós-industrial. A globalização e os avanços da tecnologia de informação e de comunicação conduzem à crescente desmaterialização de produtos, à "fluidização", à "virtualização" das relações e à "desterritorialização" da produção. Estes fenômenos, associados à necessidade de buscar padrões de produção que respeitem aspectos socioculturais, consumo consciente e sustentável, exigem ainda maior capacidade de abstração, de inovação e de flexibilidade nos projetos de design. Na visão de Silva Pinto (2016), com a mudança de valores na sociedade, os consumidores assumem a condição de coprodutores, cada vez mais conscientes da urgência de uma mudança no modo de consumo que está diretamente associado ao jeito de viver.

Novas diretrizes surgiram no cenário atual, tornando-o bastante complexo. Van der Linder (2014) explica que os problemas projetuais tendem a ser complexos no mundo contemporâneo por relacionarem fatores humanos (físicos, psicológicos, culturais, sociológicos) com fatores tecnológicos, econômicos e ambientais. No passado, o conceito de complexidade de projeto estava ligado ao tipo de produto, considerando principalmente o número de partes e componentes e os tipos de princípios de soluções (mecânicos e elétricos, por exemplo). Atualmente, o projeto de um produto tido como de baixa complexidade com base nos critérios antigos, como o projeto de um simples lápis (uma mina de grafite envolvida por madeira) pode apresentar um grau de complexidade significativo. Isso porque envolve a relação sistema-produto, ciclo de vida, logística, novos sistemas de produção que reduzem a carga física e mental dos trabalhadores, a inclusão de portadores de deficiência física e mental no sistema produtivo, certificações de qualidade, entre inúmeros aspectos jamais imaginados pelos pioneiros da indústria moderna. Para Moraes (2016), a complexidade tende a tensões contraditórias e imprevisíveis e, através de bruscas transformações, impõe contínuas adaptações e reorganização do sistema em nível de produção, das vendas e do consumo. 


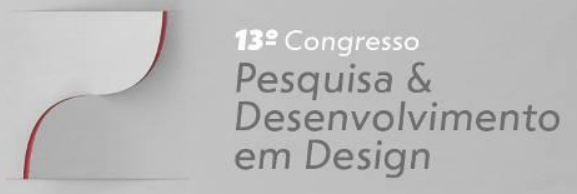

Artigo Completo

Os processos atuais de criação estão focados em suas etapas tanto quanto no produto final. Valorizam-se as etapas que precedem o projeto, como a pesquisa e a imersão no contexto em que estão inseridas as questões centrais do projeto. Os momentos anteriores à definição do problema são o início do design (MERINO, 2011). Eles devem ser objetos de maior reflexão e de análise que configuram um cenário propício para criar oportunidades, pesquisar e compreender com maior profundidade os motivos que geram as demandas do design.

Para Mendes (2012), nas fases iniciais de projeto (levantamento de dados, análise de contextos e de perfil de consumidores) pode-se valer de procedimentos como: etnografia, narrativas de vida, trajetórias de materialização, modos de uso, tecnologias e conhecimentos envolvidos. Tais procedimentos são potencialmente reveladores das dinâmicas sociais e culturais, que ligam pessoas e produtos, formas e significados e vão delineando as características do território.

Outro fator social e biológico também surge como componente desse cenário intrincado, exigindo do designer ferramentas que possibilitem opções para compreender, gerir e inovar em projetos, participando de todo o ciclo do produto. Os aspectos que envolvem a sustentabilidade tornaram-se elementos de vital importância no cenário atual. Manzini (2008) defende que considerar o ciclo de vida de um produto implica em adotar uma visão sistêmica para analisar o conjunto dos inputs e dos outputs (trocas) de todas as fases com a finalidade de prever e avaliar possíveis consequências ambientais, econômicas e sociais. Moraes (2010) afirma que com o cenário cada vez mais complexo, fluido e dinâmico é necessário estimular e alimentar constantemente o mercado por meio da inovação e diferenciação pelo design. Para o autor, o cenário passou de estático a imprevisível e repleto de códigos, tornando-se dinâmico, complexo e de difícil compreensão.

Para Cardoso (2012), o pensamento sistêmico é a maior e mais importante contribuição que o design tem para resolução dos desafios desse mundo complexo. Poucas áreas estão habituadas a considerar os problemas de modo tão integrado e comunicante. $O$ procedimento metodológico básico em qualquer atividade científica é recortar e fracionar o problema para constituir uma situação experimental passível de averiguação. Porém, "esse método funciona extremamente bem para uma série de análises, mas é de pouca valia para lidar com a elaboração de grandes sistemas complexos, sua manutenção e planejamento" (Cardoso, 2012) como aqueles que envolvem o design e geração de valor em um produto.

Para Krucken (2009), a produção de valor é influenciada por um conjunto de fenômenos que sofrem e provocam rearranjos e progressos contínuos. A desmaterialização dos produtos, a criação conjunta de ofertas, a coexistência de cadeias globais de distribuição com modelos de intermediação mais diretos entre grupos produtores e consumidores e a crescente conectividade proporcionada pela tecnologia da informação são alguns exemplos de fenômenos contemporâneos que vêm influenciando profundamente a sociedade e o modo de vida.

\section{Design e território: flexibilização dos métodos}

Os projetos com foco no território envolvem uma rede complexa, com diversos fatores envolvidos das pessoas aos recursos, passando pela produção, distribuição e seu descarte adequado. Logo, a sistematização do processo é necessária para lidar com uma grande trama de 
dados e informações, recorrendo à metodologia como uma ferramenta flexível, adaptável, aberta à intuição e à experiência do designer. Dessa forma, o design pode promover valor e melhorias em todas as etapas da cadeia produtiva, mantendo sempre a visão do processo como todo.

A metodologia surge nesse contexto com o papel de fornecer a sustentação teórica que permite ao designer atuar levando em consideração mais de um caminho e diretriz para guiar o projeto. Para Bonfim (1995), metodologia é o estudo dos métodos, técnicas e ferramentas e de suas aplicações à definição, organização e solução de problemas teóricos e práticos. Portanto, é uma ferramenta que leva em consideração o contexto do projeto para auxiliar o designer. Essa contribuição para o projeto vem a partir do conhecimento teórico que permite ao profissional a possibilidade de analisar outros métodos aplicados em contextos parecidos e adaptar ou montar as diretrizes para o cenário de seu projeto.

A metodologia deve ser levada em consideração como uma ferramenta que possibilite um leque amplo de opções, gerando flexibilidade e adaptação aos projetos considerando e aprimorando as novas diretrizes de projeto que vem surgindo. $O$ aumento de variáveis no cenário contemporâneo trouxe uma nova importância para a metodologia, pois ela é a ferramenta que permite ao designer avaliar, adaptar e escolher o caminho a ser seguido. Moraes (2010) compreende que o fato de serem colocadas no centro do debate as questões como a organização do projeto, os limites, os vínculos e os condicionantes projetuais fizeram com que a metodologia alcançasse papel de protagonista no desenvolvimento de novos produtos. Lana (2011) defende que sem método, o que resulta não é design, mas o acaso, que não permite valorização quantitativa ou qualitativa, repetição ou aprimoramento. Em contraponto, deve-se estar atento também ao acaso, que pode apontar novos caminhos assim como a intuição quando associada ao método.

A relação proposta pela metodologia entre teoria, prática e intuição é prejudicada por vários aspectos, dentre eles a dificuldade em aceitar a teoria como parte do processo. Van der Linden (2014) aponta a falta de divulgação dos métodos específicos que não constitui uma metodologia para uso acadêmico e mercadológico. O autor considera que outro viés para a abordagem de simplificação está no uso do processo criativo, como suficiente para estruturar o projeto. Dessa forma, a teoria é deixada de lado, dando espaço a um processo considerado intuitivo, mas que na verdade está reduzindo o projeto a um caminho simplista. Uma vez que a intuição, como ferramenta na tomada de decisões, está atrelada ao conhecimento teórico e prático acumulado das experiências prévias do profissional. O uso da intuição como justificativa sem esse conhecimento pode chegar a resultados gerados pelo acaso, ou sem uma argumentação própria.

Portanto, considera-se a visão de Merino (2011) ao relatar que o método ideal deve ser flexível e estar constantemente sujeito à observação crítica e avaliação, tendo em vista que os métodos servem para investigar a realidade. $O$ autor acrescenta que para construir ações que a afetam a realidade, os métodos devem manter-se constantemente no foco de atenção do designer, nunca sendo adotados como uma única etapa do processo de design sem antes serem ordenados em seu contexto crítico.

Os projetos com foco no território possuem uma rede complexa, com diversos fatores envolvidos, das pessoas aos recursos, passando pela produção, distribuição e seu retorno. Logo, um processo metodológico é necessário, no qual o designer vai atuar recorrendo à metodologia 
como uma das ferramentas para lidar com essa alta complexidade, permitindo flexibilidade, adaptação e, com o tempo, permite que o profissional utilize de sua intuição, através do conhecimento acumulado. Dessa forma, o design pode trazer uma solução que não seja pontual no sentido de atingir apenas a etapa considerada de produção, mas promover valor e melhorias em todos os pontos da cadeia produtiva, mantendo sempre a visão do processo como um todo.

\section{Estudos de caso: projetos analisados}

Três projetos foram estudados e parte de sua equipe entrevistada, construindo estudos de casos que pudessem ressaltar a questão da metodologia do design e do território no contexto contemporâneo.

A escolha dos projetos foi feita levando em consideração os aspectos de proximidade e viabilidade para a pesquisa e a diversidade de objetivos e contextos, apresentando um projeto industrial, um acadêmico e um comercial.

\subsection{Estudo de caso: Negócio Social DeLá}

O primeiro estudo de caso a ser apresentado, trata-se da Delá que possui como slogan "aquilo que é de todo lugar". A DeLá é um negócio social que oferece produtos que vão de alimentícios a utensílios e base artesanal, que buscam enaltecer os aspectos que envolvem o território como clima, relevo, solo, a matéria prima além das pessoas envolvidas, os produtores e seus modos de fazer. Há também uma preocupação em divulgar a origem e a história de cada região e produto, contribuindo para a sustentabilidade social e econômica da produção e dessa forma, garantir a perpetuação daquela prática através da geração de renda para as famílias envolvidas. O negócio busca tornar o caminho do produtor até o consumidor mais transparente, conectando os valores e qualidades do território ao longo desse processo.

A DeLá é resultado das pesquisas e experimentações da designer Laura Cota unindo atuação profissional e pesquisas realizadas em sua trajetória acadêmica como docente e como pesquisadora, da graduação ao doutorado, sempre buscando uma forma de contribuir para o desenvolvimento da agricultura e atividades familiares, seja no interior de Minas Gerais ou em outra parte do país. Um trabalho tanto científico quanto prático, que propõe experimentações durante a implementação de um empório como negócio com o propósito de ser um ponto de encontro, uma ponte que pudesse retratar ou apresentar os produtos e a realidade dos produtores, impactando os consumidores.

Inicialmente, o projeto foi pensando para o e-commerce, uma opção para inserir uma linha de produtos que não se dispõe em abundância no sistema formal enquanto outras ações inseriam o empório no mercado como a participação em feiras e eventos de design e gastronomia. Esta etapa trouxe crescimento para o negócio a cada contato feito, a cada consumidor que desejava saber a história daquele produto e de quem estava fazendo. Além de permitir a prototipagem, avaliação e ajustes de escolhas envolvendo o projeto, gerando ao final dessa etapa o nome e as peças que sustentariam esse processo de transmissão de valores e produtos entre as famílias produtoras no interior e os consumidores localizados em qualquer parte do mundo, tornando as relações globais. 
Após essa etapa inicial, foi feita a estruturação do modelo e do plano de negócio que até então era uma rede de comercialização de produtos alimentícios artesanais, sem a denominação de empório. O espaço físico foi projetado em função da identificação da necessidade dos consumidores em ver e experimentar os produtos, uma vez que a maioria eram marcas sem reconhecimento no mercado. O empório funciona então para conectar produtores e consumidores e criar um vínculo entre eles.

A proposta de valor da empresa gerada pela designer determina o comércio de alimentos de maneira justa e os valores gerados ao longo da cadeia, propondo ao invés de uma exploração dos pequenos produtores uma parceria com valores justos para todos os lados e que valorize o trabalho, agregando valor nos dois sentidos. Dessa forma, o empório contribui para a sustentabilidade social e econômica para as famílias produtoras, atende a uma demanda específica de um nicho de consumidores e o empreendimento consegue gerar lucro para se manter no mercado.

Em sua tese de doutorado ${ }^{2}$, Laura Cota (2016) destaca a cadeia de valor da DeLá, mostrando a estrutura de valorização baseada em três elementos fundamentais: as pessoas, os lugares e os produtos. Para tanto, os três processos mais importantes no empreendimento são a identificação de fornecedores, a qualificação de fornecedores e as vendas, que acontecem por meio do processo de contas histórias.

Os dois grandes atores são igualmente importantes para que o negócio funcione tanto para os pequenos produtores, famílias do interior que se sustentam com a produção artesanal de alimentos tradicionais; quanto para os consumidores, que mantêm o projeto vivo através da compra e divulgação dos produtos, ajudando cada vez mais famílias a se manterem em seus territórios de origem vivendo de suas produções de forma justa. Dessa forma, a proposta está pautada no comércio justo de alimentos, atuando como uma conexão das famílias produtoras a seus consumidores.

O processo de identificação e qualificação dos produtores segue uma diretriz padronizada, criada após estudos e análises dos requisitos. Contudo, a designer ressalta que como o modo de produção e os produtos são bem específicos, a relação com cada um é única. A DeLá ainda contribui com a parte gráfica dos produtos que chegam sem embalagem e identidade visual para aparecer nas prateleiras. A proposta é criar uma estética inicial e com o tempo e com o aumento nas vendas realizar um projeto mais sólido que contemple melhor as qualidades daquele produto.

Figura 1 - Produtos Empório DeLá

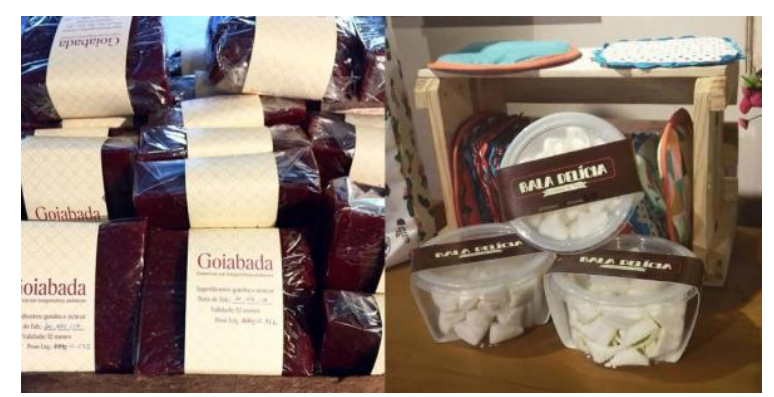

Fonte: <produtosdela.com.br/produtos/> ( 2017).

\footnotetext{
${ }^{2}$ Design relacional: uma possibilidade para a conexão, viabilização e valorização de produtos alimentícios artesanais no Brasil. PUC-RJ,Rio de Janeiro, 2016.
} 
Essa relação mesclada entre o formal e o informal é uma das bases do projeto, uma vez que o formal, muitas vezes implica em um processo rígido, que não dá conta das questões da vida cotidiana, principalmente da realidade das famílias que estão envolvidas como produtoras.

Cota (2017) completa que o foco do empório não é apenas a comercialização de alimentos, mas a valorização dos produtos e a conscientização dos consumidores a respeito da realidade vivida por quem produz e suas origens. É um projeto que lida com outras questões além de mediar essa relação; a logística, as preocupações sanitárias e a precificação justa dos produtos. É um projeto estratégico que busca atuar em toda a cadeia para garantir um direcionamento maior para os objetivos a serem alcançados.

A relação comercial proposta pelo negócio social Delá causou, e ainda causa, um estranhamento nas pessoas no primeiro momento. Os consumidores estão acostumados à relação dos supermercados onde eles lidam com grandes marcas e, na maioria das vezes, nem se lembram de que existem pessoas trabalhando por trás daquele produto. No entanto, uma vez que os consumidores criam vínculos com aquele produtor e, consequentemente aquele produto, há o início de uma relação emocional entre os dois lados deixando de ser apenas uma relação de compra. Esse aspecto está relacionado a um dos objetivos do projeto: a mudança de olhar do consumidor, garantindo a ele que os produtos oferecidos sejam de qualidade por sua origem e que existe uma história que vale a pena junto daquele produto. Se eles estão ali é por que passaram por um crivo de qualidade e verificação, por isso são merecedores de credibilidade e respeito.

O olhar do produtor também foi trabalhado para que o empório pudesse funcionar. A diretriz principal, nesse sentido, é o conceito de parceria, sendo o negócio social DeLá uma representante dos produtores e suas mercadorias e não apenas um ponto de revenda visando alta lucratividade como uma estratégia de marketing apenas. Essa parceria é verdadeira e importante para garantir a relação justa já que leva a uma troca benéfica a todos, diferente de uma relação unilateral e que explora os produtores.

No caso do negócio social DeLá, o design é utilizado do nível estratégico ao operacional da empresa, percorrendo todas as etapas da cadeia com uma construção participativa de produtores e consumidores. A coordenadora relata em entrevista que esse modelo está em consonância com a maneira como atualmente as empresas têm feito, indo além do projeto de objetos e marcas. 0 aspecto relacional tem ganhado destaque nos últimos anos, já que se tornou imperativo um esforço conjunto (coparticipativo) para a resolução criativa de problemas complexos da sociedade, como a condição de desigualdade e injustiça em que vivem diversos produtores artesanais de alimentos no Brasil. O SEBRAE (2011) defende que o design passou a interagir cada vez mais com profissionais de áreas situadas tanto no início do processo, como planejamento, administração e marketing, quanto no final, como de engenharia, logística, controle de qualidade e vendas. Essa função trouxe o design para o planejamento estratégico e posicionamento das empresas no mercado, aproximando a atuação a outras áreas de conhecimento.

A coordenadora do projeto considera a DeLá como um caminho de experimentação. Não há verdades estabelecidas, mas a busca por se fazer melhor e de maneira diferente o comércio de alimentos artesanais tradicionais no Brasil. Uma referência para outros negócios de outra natureza. Os aspectos territoriais entram como componentes fundamentais na diferenciação dos produtos e do modelo no mercado, sendo um elemento reconhecido por consumidores e por 
produtores. A experimentação da empresa DeLá também mostra que é possível romper com a lógica de desvalorização de produtos artesanais brasileiros, utilizando o design para valorizar os territórios (seus produtos, pessoas e tradições), a partir da mudança de relação que se estabelecem com eles.

Para a designer, Laura Cota, as ações e projetos que envolvem o território estão diretamente ligados ao valor identitário e a preocupação com a sustentabilidade de todo o processo, associada à consolidação de pensamentos de designers, filósofos, administradores e outros, formando uma rede capaz de promover uma solução que lide com a complexidade do contexto.

\subsection{Estudo de caso: Programa Bem Maior}

O Bem Maior é um programa de extensão sediado na Escola de Design da UEMG (Universidade do Estado de Minas Gerais). O Programa tem como premissa a capacitação de jovens de baixa renda em diferentes ofícios, trabalhando o empreendedorismo com o objetivo de gerar renda desenvolvendo os produtos que já são produzidos pela comunidade daquele território.

Existem dois projetos distintos no programa: o "Muda de Ideias" que trabalha com jovens de 14 a 21 anos e promove o desenvolvimento de produtos em serigrafia e o "Colmeia", que trabalha com uma casa de acolhimento de adolescentes grávidas. A proposta do Muda de Ideias é ser um dos projetos do Programa Bem Maior, voltado para a geração de renda e capacitação por meio do design social. O Muda de Ideias foi projetado com a duração de nove meses e trabalha com a técnica de serigrafia junto aos jovens do Bairro Nacional em Contagem, sendo essa comunidade escolhida pelo interesse dos jovens em desenvolver seus produtos e a economia local, gerando uma oportunidade de sustento (Figura 2).

Figura 2 - Oficina e produtos do Programa Bem Maior

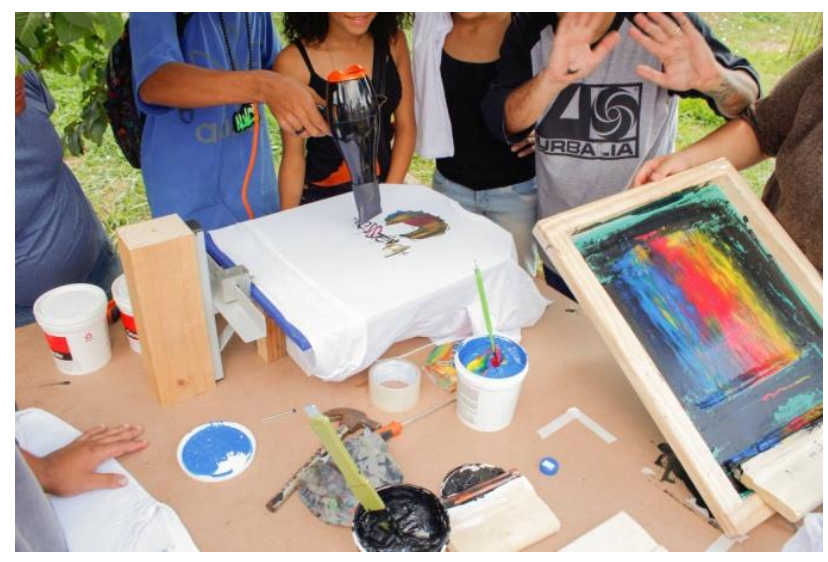

Fonte: Acervo da Pesquisa, 2017.

A coordenadora do projeto relata, em entrevista, que a ideia surgiu de sua experiência extensionista em design social, notando que o problema estava não só na geração de renda, mas também na capacitação da população dessas áreas. Muitos projetos bons traziam pouco retorno aos participantes em termos de renda e desenvolvimento apesar do impacto social efetivo. A ideia da serigrafia vem como uma opção adaptada à realidade da comunidade do Estrela D'alva, em que o projeto está inserido, já que é uma técnica que pode ser realizada com maquinários mais simples e com diversas possibilidades de aplicação e suportes. 
O projeto foi planejado e construído de maneira colaborativa, montando uma estrutura que não exclui, aceitando todos os jovens do bairro interessados em participar. Prevê também uma organização horizontal e a utilização da cultura e sua valorização como diferencial para os produtos ali produzidos. Para essa construção, a coordenadora contou com reuniões com uma equipe formada por designers estudantes bolsistas que discutiram as dinâmicas daquele território, os problemas, conceitos e diretrizes que serviriam como base para o planejamento e a condução dos projetos que estão inseridos no programa.

Após esse trabalho inicial de estabelecer as diretrizes para o projeto, foi realizada a etapa de identificação de territórios, comunidades onde o projeto pudesse atuar. Segundo a designer e coordenadora do projeto, algumas comunidades manifestaram interesse e receberam preferência, pois esse desejo das pessoas era um requisito importante para que o projeto pudesse ser iniciado.

O método proposto pelo programa Bem Maior prevê um nivelamento da equipe, no qual são passados os valores e metodologia de trabalho antes de iniciar a atuação no território. Essa é uma etapa essencial para a contextualização dos envolvidos na realidade daquela comunidade. Em seguida, a equipe realiza um estudo sobre o processo que será aplicado na comunidade e sobre a própria comunidade. Essa fase já funciona como uma prototipagem do processo que será aplicado. Essa aplicação real também prevê uma cocriação com as pessoas que vivem ali, buscando uma proposta horizontal sem imposição de qualquer tipo para essa comunidade.

A identificação e a conexão de possíveis parceiros são feitas, principalmente, por network. Segundo a coordenadora, os próprios parceiros acabam indicando novas pessoas para participar, criando uma rede que conecta pessoas com o mesmo objetivo. A própria comunidade também aproveita e contribui com esse processo, oferecendo indicações de pessoas que já ajudam ou com as quais eles têm interesse de interagir.

Sobre a construção do método e o uso de ferramentas metodológicas na construção do processo, a coordenadora enfatiza a importância da experiência e do referencial teórico acumulado por toda a equipe em duas frentes: primeiro, entre a equipe para criar o diagnóstico de cada comunidade e posteriormente, dessa equipe com a participação da comunidade, que busca executar os ajustes do projeto de forma que se adeque à realidade local.

Vanucci (2017) ainda ressalta a atuação sistêmica e por toda a cadeia como sendo a essência do projeto, utilizando o design pra percorrer o Programa desde a concepção, pois não é interessante nem para a equipe nem para a comunidade trabalhar apenas na melhoria dos produtos. A ideia é criar um sistema que possibilite que a comunidade possa observar as mudanças, aprender e ser capaz de criar uma independência, uma autonomia sobre todo o processo, da concepção do produto até as formas de comercialização. O projeto ainda prevê etapas de manutenção e acompanhamento após o período de implantação.

O processo metodológico entra como fator diferencial desde a etapa de diagnóstico, no qual são considerados as riquezas culturais, as habilidades e os interesses da comunidade e as potencialidades do território, esses aspectos de projeto tornam as etapas de pré-projeto e contextualização essenciais para o seu desenvolvimento. Além disso, essa visão de construir a metodologia ao longo da criação do projeto requer uma flexibilidade e um referencial que permita essas adaptações durante o processo.

Por fim, a cocriação no projeto e na sua aplicação é uma diretriz que não era prevista no processo moderno, até pelo modelo de atuação pontual do design. Sendo assim, essa prática 
exige um método e dinâmicas específicas que possibilitem a interação entre os membros da equipe ao gerar uma solução. A cocriação também cria uma conexão entre a equipe e a comunidade ao elaborar uma proposta em conjunto, buscando integrar os participantes no processo, valorizando- os e tornando o projeto parte de sua realidade.

O projeto cria seu método à medida que vai avançando nas etapas previstas na sua fase inicial, adaptando as atividades e ferramentas aplicadas a realidade da comunidade trabalhada e, consequentemente, ao território que ela pertence.

\subsection{Estudo de caso: Cervejarias Mineiras}

O projeto cervejarias mineiras traz uma proposta de estratégia coletiva para um grupo de cervejarias artesanais de Minas Gerais, realizado pelo Senai-CECOTEG ${ }^{3}$ para atender uma demanda do Sindbebidas MG (Sindicato das Indústrias de Cervejas e Bebidas em Geral do Estado de Minas Gerais). A proposta inicial era a criação de um tipo de "selo" para unir essas empresas e garantir identidade e visibilidade à cerveja mineira. No desenrolar do projeto, ficou comprovada a necessidade de um plano estratégico, englobando diversas outras ações para tornar a proposta de fato efetiva.

A criação do selo partiu da investigação sobre qual seria o valor dessa identificação, um selo de qualidade ou de indicação geográfica. Porém, para a produção de cerveja os aspectos de produção não são diferenciais, considerando que o modo de fazer cerveja é padrão no mundo inteiro, a produção artesanal de cervejas é um processo repleto de normas e regras de controle e de qualidade. O maior desafio para criação de um selo se apresenta em como trazer um diferencial para um produto, que tem obrigatoriamente que seguir um resultado previsto por um livro de regras? As questões territoriais contribuem justamente para gerar esses valores diferenciais, que nesse caso, estão na própria composição do grupo de cervejarias no território mineiro. Nesse projeto, devido à forma de fabricação da cerveja, o território entra como o aspecto para diferenciação em relação a outras cervejas. Dessa maneira, identificar os valores mineiros nesse processo é o que torna essa proposta de marca algo que pode de fato transmitir para o consumidor uma experiência específica das cervejas mineiras.

A demanda surgiu da dificuldade real quanto ao tamanho das cervejarias que, apesar da quantidade, são micro e pequenas empresas, pouco competitivas em relação às grandes cervejarias. Existe o reconhecimento de que as cervejarias estão negociando um produto com um bom valor de venda, entregando uma cerveja com ingredientes, processos e qualidade melhor do que a cerveja considerada mainstream, ou seja, a cerveja oferecida pelas grandes marcas, mas sem competitividade por diversos aspectos, principalmente de divulgação e compatibilidade de preço e público. A ideia de coletividade vem justamente para dar voz para que esse grupo possa competir com as grandes marcas, melhorando o cenário pra elas e para o setor.

O projeto ainda está em execução e consiste de oito etapas metodológicas para o seu desenvolvimento. A primeira etapa foi uma compreensão do setor por meio de entrevistas qualitativas e dados quantitativos, mais voltados para o consumidor (com foco no cliente), mas ainda sim, buscando um caráter qualitativo. Foram realizadas visitas técnicas às cervejarias e questionários para os donos sobre as dificuldades, expectativas e o cenário em geral da cerveja artesanal. Também foram realizadas entrevistas com formadores de opinião como especialistas,

\footnotetext{
${ }^{3}$ Centro de Comunicação, Design e Tecnologia Gráfica
} 
jornalistas da área e pessoal dos pontos de venda como bares, restaurantes e supermercados que forneceram muitas informações sobre o cliente consumidor, que também foi pesquisado na internet. $O$ projeto também se baseou em uma extensa pesquisa bibliográfica que foi realizada para entender a história da cerveja, sua produção e atributos. Na trajetória da pesquisa, buscou-se compreender porque tantas cervejarias artesanais estão surgindo em Minas Gerais, e quais são os atributos identitários relacionados a essa grande produção no estado.

Na Figura 3, à esquerda, está em evidência uma representação da localização dos produtores de cervejas artesanais somente na Região Metropolitana de Belo Horizonte. À direita, um mapa interativo destaca a localização das principais cervejarias artesanais de Minas Gerais. De acordo com o SindBebidas, são 41 cervejarias artesanais no Estado, sendo que, 15 estão localizadas no município vizinho à capital. A cidade de Nova Lima fornece incentivos fiscais a esse tipo de negócio, o que explica a formação do pólo da cevada na região da cidade, conforme Ayer (2017).

Figura 3 - Mapa da localização dos produtores de cervejas artesanais somente na Região Metropolitana de Belo Horizonte (direita) e um Mapa interativo destaca das principais cervejarias artesanais do Estado (esquerda).

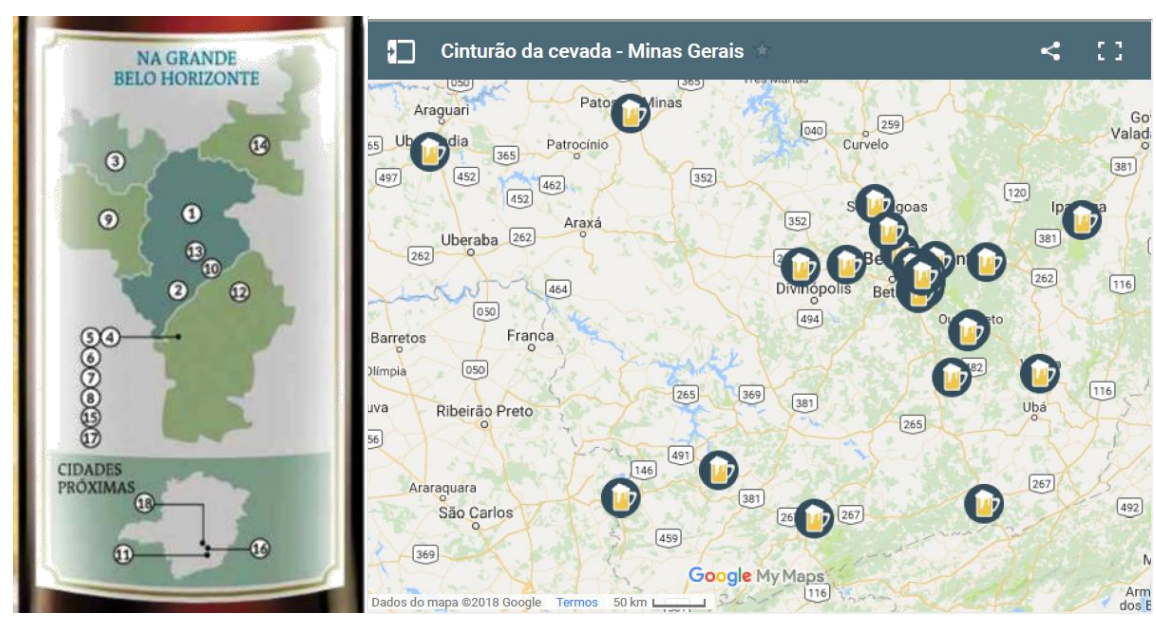

Fonte: AYER (2017)

Após o levantamento dos dados, na segunda etapa, foi construída uma matriz SWOT4 para consolidar as informações coletadas e permitir análises, sendo essa uma ferramenta de planejamento estratégico que permite a compreensão do negócio para as tomadas de decisão de forma geral e aplicadas também ao design, tendências de comportamento, consumo, expectativas dos consumidores, olhar o passado e o futuro. As informações iniciais para consolidar um resultado para o cliente e direcionar o projeto para a próxima etapa foram organizadas.

A metodologia foi construída junto com o projeto, utilizando um método de trabalho com uma visão 360 graus do contexto e do projeto, analisando sob várias óticas: dentro, quem somos nós (as cervejarias), o setor, a história construída e para fora: o que o mercado e tendências estão falando, o que os concorrentes estão fazendo quais as referências e inspirações; para trás: olhar a história, as forças e o que tem sido feito, e para frente, ambições e aonde se quer chegar, direcionamento do projeto.

A terceira etapa foi de modelagem de negócio, pensar o que esse planejamento estratégico seria, baseado no pensamento coletivo. Uma decisão tomada por todas as partes participantes do projeto que envolvia profissionais de diversas áreas entre gestores, designers, 
advogados, empresários e outros. Essa marca coletiva deveria ser responsável por promover o desenvolvimento das empresas, do setor e a coletividade, pautada em uma diretriz estratégica para guiar outras ações além da divulgação, como as compras, a distribuição e outras ações que estão no plano da gestão do negócio. Cabe a essa marca proteger o patrimônio intelectual da cerveja mineira, o modo de fazer, que diz tudo sobre quem somos e esse seria o valor principal desse projeto.

A mudança no cenário econômico permitiu às pessoas terem acesso a cervejas e experiência de outros países, seja pelo turismo ou pela importação. Essa nova visão permitiu que as cervejas artesanais pudessem ter um espaço maior no mercado, proporcionando justamente a experimentação, a sensação de degustar algo novo. Ao pesquisar cervejarias de outros estados, ficou claro que as características das cervejarias mineiras não eram atributos comuns de todas as empresas do ramo, mas sim valores que eram de Minas Gerais, de território. Uma vez que a cerveja mineira está muito ligada à experimentação, à cozinha mineira, e ao cuidado detalhado durante o processo de produção, tornando esse um atributo de território que pode ser explorado como diferencial.

Posteriormente, numa quarta etapa, foi realizada uma pesquisa de "mineiridade" utilizando de referências bibliográficas, com o devido cuidado para não sofrer influência pelos dados já obtidos anteriormente, buscando novas percepções para garantir um resultado que pudesse ser comparado com os anteriores. Estes resultados serviram de base para a pesquisa com o objetivo de identificar e verificar os "atributos do ambiente mineiro", em relação aos demais territórios no Brasil.

As diretrizes estratégicas e os perfis dos clientes, tanto interno (pessoas engajadas com a marca, pessoas associadas pelo benefício e parceiros) quanto o cliente externo (aquele que ia perceber de fato a marca) foram decisivos para a experiência do produto. Foi utilizado também um mapa de posicionamento para identificar onde seria a localização mais relevante para aquele negócio no mercado, justificando a proposta de valor.

O projeto encontra-se na quinta etapa, a de desenvolvimento de marca. Porém, o método até então apresentado durante o projeto, mostra o design atuando como tradutor, mediador e coordenador das etapas e escolhas. Através do relato das designers à frente do projeto, Angélica Ferraz e Cristiane Araújo, podemos observar a visão sistêmica na qual as etapas se completam e guiam o projeto para um ciclo que revisam as informações, tornando as tomadas de decisão mais assertivas.

A transversalidade aparece, principalmente, na busca por ferramentas de outras áreas que contribuem quando aplicadas na consolidação das informações para os clientes já que essa é uma necessidade formal do projeto, além de evidenciar que é realmente relevante para ser utilizado como base projetual.

O design e a forma de projetar são estratégicos, porque envolvem aspectos como a compra de materiais para a fabricação do produto, a logística, a divulgação, a comunicação com o cliente e, principalmente, a experiência para esse cliente. No caso desse projeto a proposta está associada à coletividade, propondo melhorias para o grupo e setor. As conexões visadas por uma proposta estratégica requerem atenção de uma perspectiva do todo, das relações intra e interetapas, fechando assim um sistema coerente e capaz de entregar uma proposta de valor que vai realmente impactar em toda a cadeia. 
Ainda sobre o método, os profissionais de design envolvidos ressaltam a construção dele durante o desenvolvimento do projeto, a importância dessas ferramentas como forma de confirmação das suas percepções como designers e o suporte frente aos clientes como argumentos reais para sustentar as diretrizes propostas.

\section{Considerações Finais}

A elaboração desse trabalho foi motivada pelo interesse em projetos que abordam o território como um aspecto chave dentro da prática projetual. As rápidas transformações pelas quais passa não só o design, mas toda a sociedade vem impondo a necessidade de adaptações de toda ordem e em todas as áreas do conhecimento.

Foi realizada uma reflexão acerca da metodologia do design, sobre como as mudanças na sociedade e no mercado alteraram as dinâmicas de projeto e qual o papel da metodologia no contexto contemporâneo, novas abordagens metodológicas projetuais aplicadas nesse cenário foram estudadas.

As propostas contemporâneas apontam para uma atuação cada vez mais sistêmica e interdisciplinar, no qual o designer deve ter uma visão do todo e de cada etapa, além de trazer ferramentas novas e de outras áreas que possam contribuir para a construção do processo. Não é mais possível fixar-se em modelos de estrutura projetual padrão para diferentes projetos e realidades com diferentes contextos e territórios. A flexibilização nos processos é fundamental para oportunizar possibilidades inovadoras em design.

Nos estudos de casos, ressalta-se a importância das etapas iniciais de projeto, como a pesquisa e o aprofundamento no território que será trabalhado. Proporcionaram também uma melhor compreensão sobre o uso de ferramentas e pensamentos de outras áreas dentro de um projeto de design, exemplificando aplicações e objetivos. Analisando cada um dos métodos aplicados, pode-se destacar a especificidade de cada um, a construção de cada etapa e aplicação de uma ferramenta dentro de um contexto único. Essa propriedade torna importante o registro desses projetos, pois a falta de referência foi um problema encontrado na etapa inicial ao buscar projetos que tratavam de um contexto ou complexidade semelhante.

Os projetos de design que envolvem o estudo territorial são de natureza complexa e exigem uma visão ampliada e sistêmica. Os atributos territoriais devem agregar valor identitário aos processos, produtos e serviços. Devem assumir o compromisso com a sustentabilidade social, econômica e ambiental, posicionando o design em seu papel na contemporaneidade. Os casos apresentados têm o território como centro do projeto e comprovam a necessidade de uma estrutura projetual com recursos e caminhos que possibilitem ao designer conduzir as escolhas buscando um método coerente para aquele contexto. Essa dinâmica em que o método é construído durante o projeto é uma característica recorrente entre os casos estudados e confirma o caminho pelo qual o design deve ser sistêmico e transversal para abranger todos aspectos envolvidos.

Acredita-se na necessidade de criação de uma base teórica para futuros projetos e estudos nessa área, uma vez que essa fundamentação é uma das ferramentas que o designer tem para lidar com cenários variáveis. Assim, a metodologia se estabelece na flexibilidade e capacidade de 
adaptação das etapas projetuais, permitindo novas possibilidades para o projeto.

Para a difusão e aplicação de novos métodos no exercício profissional do design será preciso um aprofundamento deste estudo em futuras pesquisas. Pretende-se ampliar a discussão na academia visto que os estudos metodológicos exigem versatilidade e criatividade. 0 entendimento da flexibilização, redirecionamento dos projetos e uso da intuição são fatores compatíveis com a aplicação dos métodos apresentados. Assim, as relações com os territórios demandam aprofundamentos e formas específicas de lidar com os contextos de projetos e coautorias.

\section{Referências}

AYER, Flavia. Minas terá um selo para atestar a qualidade a qualidade da produção de cervejas artesanais no estado. Postado em: 02 abr. 2017. Disponível em: <https://www.em.com.br/app/noticia/economia/2017/04/02/internas_economia,859098/minastera-selo-para-atestar-a-qualidade-de-cervejas-artesanais.shtml>. Acesso em: 03 abr. 2018.

BELLS, D. O advento da Sociedade Pós-Industrial. São Paulo: Cultrix, 1974.

CARDOSO, Rafael. Design para o mundo complexo. São Paulo: Cosac Naify, 2012.

COTA, Laura. Design relacional: uma possibilidade para a conexão, viabilização e valorização de produtos alimentícios artesanais no Brasil. PUC-RJ, Rio de Janeiro, 2016.

GANEM, Márcia. Design Dialógico: gestão criativa, inovação e tradição. São Paulo: Estação das Letras e Cores, 2016.

KRUCKEN, Lia. Design e Território: valorização de identidades e produtos locais. São Paulo: Studio Nobel, 2009.

KRUCKEN, Lia. Competências para o design na sociedade contemporânea. In: Moraes D. J; Krucken, L. (Org). Cadernos de estudos avançados em design: transversalidade. Barbacena: EdUEMG, 2Ed, 2016.

LANA, S. L. B. A complexidade dos métodos em design. In: Moraes D. J; Dias R. A; Conselho R. B. (Org). Cadernos de estudos avançados em design: método. Barbacena: EdUEMG, 2Ed, 2016.

MANZINI, Ezio; VEZZOLI, Carlo. O Desenvolvimento de Produtos Sustentáveis. São Paulo: EDUSP, 2008.

MERINO, Giselle; GONTIJO, L. A; MERINO, Eugenio. O percurso do design: no ensino e na prática. In: Moraes D. J; Dias R. A; Conselho R. B. (Org). Cadernos de estudos avançados em design: método. Barbacena: EdUEMG, 2Ed, 2011.

MORAES, Dijon Design e complexidade. In: Moraes D. J; Krucken, L. (Org). Cadernos de estudos avançados em design: transversalidade. Barbacena: EdUEMG, 2Ed, 2016.

MORAES, Dijon Design. Metaprojeto: o design do design. São Paulo: Blucher, 2010.

SILVA PINTO, Laura de Souza Cota Carvalho. Design relacional: uma possibilidade para a conexão, viabilização e valorização de produtos alimentícios artesanais no Brasil. Rio de Janeiro, 2016.

VAN DER LINDEN, J. C; LACERDA, A. P. Pelos Caminhos do Design: metodologia de projeto. São Paulo: EDUEL, 2012. 